\title{
Towards Lean Product and Process Development
}

\author{
${ }^{1}$ Khan, Muhammad; ${ }^{1}$ Al-Ashaab, Ahmed; ${ }^{1}$ Shehab, Essam; ${ }^{2}$ Haque, Badr; \\ ${ }^{3}$ Ewers, Paul; ${ }^{4}$ Sorli, Mikel; ${ }^{4}$ Sopelana, Amaia; \\ ${ }^{1}$ Cranfield University, Manufacturing Department \\ ${ }^{2}$ Rolls-Royce Plc, Engineering Systems \& Service \\ ${ }^{3}$ Visteon Engineering Services Ltd., Electronics Product Group \\ ${ }^{4}$ Tecnalia, Innovation Systems Unit
}

\begin{abstract}
Successes in lean manufacture have led researchers and practitioners to consider extending 'lean' to different parts of the engineering enterprise, including product and process development (PPD). Lean product development (PD) has been understood to mean lean manufacture applied to PD, while the roots of lean PD just like lean manufacture - go back to Toyota. This paper presents the methodology adopted in order to pave the way towards a coherent lean PD model that combines lessons from the Toyota PD system (TPDS) with other best practises. The paper provides a unique review of the lean PD research area, and a reference framework for the enablers that Toyota has employed for lean PD. An investigation of five engineering enterprises undertaken to search for evidence of the implementation of lean PD enablers through observation, document analysis and interviews is also presented. Some enablers have been informally applied, while few have been formally implemented, and no model was found to formally combine Lean PD enablers into a coherent whole. This is the first paper to critique attempts to describe lean PD and provide a definition for Lean PD.
\end{abstract}

Keywords: Lean product development; Toyota development; product development; product design; (set-based) concurrent engineering; continuous improvement; process modelling; design for manufacture; process innovation; knowledge (based) engineering;

\section{Introduction}

The challenges faced by engineering companies are fierce and many find themselves struggling for mere survival. The entire engineering enterprise is being compelled to improve; some of the pressures include economic crises, evolving market demands, stiff global competition, and the need to improve time-to market (Yelkur and Herbig 1996; Murman et al. 2000; Molina et al. 2005; De Brentani 2010). Lean thinking - an improvement 
philosophy which focuses on the creation of value and the elimination of waste - is a potential weapon in this struggle.

Lean thinking has been a subject of research for nearly two decades, the focus of which has been on improving manufacturing processes (Khalil and Stockton 2010), as well as administration, management and the supply chain. However new engineering products continue to under-perform in their lead times, cost, and quality. There has been comparatively less research done to apply 'lean' to product and process development (PPD): the design process, from the concept stage to the detailed development of products and their related manufacturing processes. This is rather strange, as PPD has the greatest influence on the profitability of any product (Duverlie and Castelain 1999). One possible reason for this is the 'room for creativity' and subsequent unstructured approach in traditional product design. Research undertaken to improve PPD with lean thinking may prove instrumental in the progress of engineering.

The term lean product development (PD) has been understood to mean lean manufacturing applied to PD, while the roots of lean PD - just like lean manufacturing - go back to Toyota. However, researchers and practitioners have taken various routes in their attempts to describe or propose an approach to lean product development. Through this research the authors seek to define lean PD and its supporting constituents.

This paper presents a review and analysis of the lean PD research area, and investigates the various approaches taken by researchers and practitioners. Based on the review a framework for the enablers of lean PD has been proposed which provides a foundation for the building blocks of lean PD. The paper also describes the outcome of an industrial field study of five engineering enterprises, undertaken to search for evidence of the implementation of lean PD enablers.

The research presented in this paper has been conducted as part of a collaborative European research project titled 'Lean Product and Process Development (LeanPPD). The project initiated in January 2009 and expected to conclude by January 2013 - is supported by the European Commission for research (FP7/NMP-2008-214090).

The structure of the paper follows the sequence of research, which begins with a description of the research approach in section 2, followed by a brief background to lean manufacturing and subsequently lean PD in section 3. Different approaches to lean PD are analysed in 
section 4 and an overall analysis of the research area and the research that is required to progress towards a holistic implementation of lean PD is provided in section 5. The paper then presents a reference framework for lean PD enablers in section 6, followed by the results and analysis of an industrial field study undertaken to search for evidence of the implementation of lean PD enablers in section 7. Section 8 provides a number of conclusions drawn from the research presented and recommendations for future work.

\section{Research Approach}

The authors have endeavoured to analyse the work done in the lean PD research area, understand the different approaches and identify some research trends in the field. Approaches have been classified in order to provide an overview of the research area, research gaps have been identified, and future research in this area is proposed. The employed research approach is depicted in Figure 1.

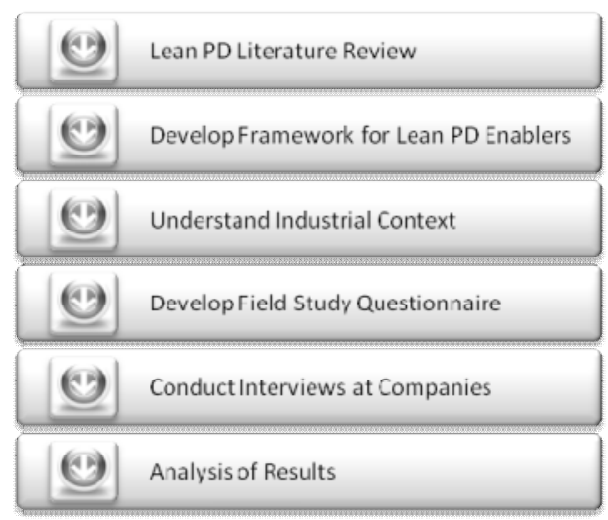

Figure 1 - Research Approach Diagram

In order to identify relevant literature a number of methods were employed. Keyword searches were used across a number of databases including Scopus, ProQuest, Springerlink, Emerald, and Science Direct. Keywords that were used include: lean product development, lean model, lean design, lean engineering, product development value, amongst others. The searches resulted in hundreds of journal and conference papers which were reviewed and 
filtered. Library searches and internet websites (e.g. Amazon) were also used to identify other literature such as text books.

Another technique that was employed was backtracking through the references of the relevant papers. The resulting literature has been analysed in section 4 . In order to develop a clearer understanding of lean PD, a framework was developed in order to structure the building blocks of lean PD (enablers). This framework was based on content analysis of the reviewed literature and includes the techniques, and tools that form the foundation of lean PD. The framework is presented as a table in section 7: The Building Blocks of Lean PD.

Five engineering companies from the automotive, aerospace and home appliances sectors were visited and observed by researchers in order to develop an understanding of the context. The needs and interests of each company were understood through various exercises involving both face to face and virtual teleconference meetings. The purpose of these activities was to understand how lean PD could help the companies to improve their PD. This interaction with industry is part of the clinical methodology that has been employed, wherein researchers adopted a collaborative approach with companies and plan to have an active role in the implementation of theory and analyse the impact of their research.

Based on the understanding gained from the literature review and industrial visits, a structured questionnaire was developed in order to search for evidence of the implementation of lean PD enablers. This was a difficult task as the questions had to address multiple lean PD enablers simultaneously and took over three months to develop. The questionnaire was used to guide the explorative study through face to face interviews with managers and engineers. Thirty seven employees were interviewed from the five companies both in small groups and individually to get a rich set of results. The results from these interviews were later analysed and conclusions were drawn.

\section{The Foundation of Lean Product Development}

Lean has become one of the most popular words in engineering improvement initiatives. In the foundation book 'The Machine that Changed the World (Womack et al. 1991), the term 'lean' was described as a combination of principles and ideas developed by Toyota and 
described earlier by Taichi Ohno (Ohno, 1988) to describe the Toyota production system. Further work in 1996 titled 'Lean Thinking', detailed important aspects such as value, waste, and the five core lean principles (Womack and Jones, 2003).

The term lean was initially used in reference to manufacturing operations; lean is now being used across a spectrum of sectors. The term lean has become confusing as some label Toyota practise as lean (Womack et al. 1991), while others label good practise as lean (Mynott 2000). Lean thinking is no doubt based on Toyota methods, and much of the lean literature describes Toyota practises. Baines et al. (2006) identified a difference between earlier works, where the focus was on waste elimination and latter works that which focused on value creation. One reason for this may be because earlier works focused on manufacturing operations whereas latter works attempted to apply the same principles to different settings. Browning (2002) draws a similarity between engineering and an athlete, and argues that simply losing weight will not allow you to win a race. He quotes a number of cases where companies have over-emphasised on efficiency which resulted in lost production and sales, although such a causative relationship is not easy to prove. Lean manufacturing has evolved as its own discipline, and many have tried to adopt lean manufacturing principles to other parts of the engineering enterprise. However, one of the questions addressed in this paper is: should the source of lean PD be the evolved lean manufacturing discipline or Toyota PD?

The term 'lean production' was first published by John Krafcik in a Sloan Management Review article in 1988, (Krafcik, 1988) based on his master's thesis at the MIT. Krafcik had been a quality engineer in the Toyota-GM New United Motor Manufacturing (NUMMI) joint venture in California before his MBA studies at MIT. Krafcik's research was part of the International Motor Vehicle Program (IMVP) at MIT, which resulted in the aforementioned book 'The Machine That Changed the World' (Womack et al. 1991). Prior to the term 'lean', the Toyota production system was referred to as 'fragile' perhaps due to the scepticism of the US researchers who initiated the case study. The IVMP program actually had two initial phases, both led by Professor Daniel Roos, the founding director of MIT's engineering systems division. The first 5-year research program began in 1979 aimed at understanding the future role of the automobile, while the second 5-year program began in 1985 aimed at measuring and describing the gap between the Western World and Japan (Holweg 2007).

While the focus of research at MIT was on the Toyota Production System (TPS), Allen Ward, a professor of mechanical engineering at the University of Michigan (UM) was more 
concerned with product development (PD). Allen had initially completed his $\mathrm{PhD}$ at MIT - at the same time as the IVMP - in artificial intelligence for automating engineering design, wherein he realised that conventional PD was fundamentally flawed and stumbled upon what he coined set-based concurrent engineering (SBCE): a unique PD process (Sobek et al. 1999; Ward 2007).

Allen Ward later joined UM and continued in this research area and he began a case study with a number of $\mathrm{PhD}$ students and later Jeffrey Liker, a professor of industrial and operations engineering. Allen was considered as the leading US authority on Toyota's product development process and was the technical expert for a two-year collaborative project with the National Center for Manufacturing Sciences in Michigan. The project (initiated by GM/Delphi) titled 'Product Development Process- Methodology and Performance Measures', aimed to understand how to make substantial PD improvements by studying world class companies that had distinguished themselves with a combination of high quality products and fast time to market (Kennedy 2003).

\section{Approaches to Lean Product Development}

Researchers and practitioners took different journeys once they realised the potential benefit that PD could gain by becoming 'Lean'. These approaches may be separated into five categories, presented in Table 1:

(1) Those who rebranded concurrent engineering as Lean PD

(2) Those who viewed 'Lean' as lean manufacturing - as described in the various texts analysing TPS - and tried to adapt the various constituents to make sense to PD; in some cases lean manufacturing was mixed with other theories and approaches in order to ensure the proposed Lean PD approach was relevant to PD

(3) Those who appreciated the foundation of Lean PD to be the Toyota product development system (TPDS), but - probably due to the lack of literature on the topic - incorporated some elements of TPDS into the five lean principles combined with other ideas from lean manufacturing and tried to apply this combination to PD

(4) A fourth group that identified the foundation of 'lean' to be Toyota and went to great extents to study TPDS from the Toyota Motor Company and identified a more 
comprehensive set of principles and mechanisms directly related to PD that were argued to be theoretically superior to any of the PD theory that was previous identified.

(5) A fifth group has recently emerged where practitioners have attempted to apply Toyota PD concepts in their companies; this group is reliant on group 4 for their principles and mechanisms

All of these groups used Toyota's success to support their approaches; however, Toyota's success was not achieved by the approaches described by groups 1-3. Rather Toyota's success was due to the approach that they themselves adopted and their PD practices may have contributed significantly. This means that only the researchers that focused purely on TPDS can justify such a claim (groups 4-5).

Table 1 Approaches to Lean Product Development

\begin{tabular}{|c|c|c|c|c|}
\hline Approach & Author & Year & Title & Source/Publisher \\
\hline $\begin{array}{l}\text { Rebranding } \\
\text { concurrent } \\
\text { engineering as } \\
\text { Lean PD }\end{array}$ & $\begin{array}{l}\text { Karlsson and } \\
\text { Ahlstrom }\end{array}$ & 1996 & $\begin{array}{l}\text { The Difficult Path to Lean Product } \\
\text { Development }\end{array}$ & $\begin{array}{l}\text { Journal of Product } \\
\text { Innovation Management }\end{array}$ \\
\hline \multirow{5}{*}{$\begin{array}{l}\text { Adapting ideas } \\
\text { from Lean } \\
\text { Manufacture to } \\
\text { PD in } \\
\text { combination } \\
\text { with other } \\
\text { theories }\end{array}$} & Mynott & 2000 & Lean Product Development & $\begin{array}{l}\text { American Technical } \\
\text { Publishers }\end{array}$ \\
\hline & Fiore & 2003 & $\begin{array}{l}\text { Lean Strategies for Product } \\
\text { Development }\end{array}$ & Quality Press \\
\hline & $\begin{array}{l}\text { Cooper and } \\
\text { Edgett }\end{array}$ & 2005 & $\begin{array}{l}\text { Lean, Rapid and Profitable New } \\
\text { Product Development }\end{array}$ & $\begin{array}{l}\text { Product Development } \\
\text { Institute }\end{array}$ \\
\hline & $\begin{array}{l}\text { Anand and } \\
\text { Kodali }\end{array}$ & 2008 & $\begin{array}{l}\text { A Conceptual Framework for } \\
\text { LNPD }\end{array}$ & $\begin{array}{l}\text { International Journal of } \\
\text { Product Development }\end{array}$ \\
\hline & Reinertsen & 2009 & $\begin{array}{l}\text { The Principles of Product } \\
\text { Development Flow }\end{array}$ & Celeritas Publishing \\
\hline \multirow{3}{*}{$\begin{array}{l}\text { Integrating } \\
\text { elements of } \\
\text { TPDS with } \\
\text { Lean } \\
\text { Manufacturing } \\
\text { principles and } \\
\text { methods and } \\
\text { applying them } \\
\text { to PD }\end{array}$} & $\begin{array}{l}\text { Haque, } \\
\text { James- } \\
\text { Moore and } \\
\text { Broughton }\end{array}$ & 2002 & $\begin{array}{l}\text { Application of Lean Principles to } \\
\text { Product Introduction }\end{array}$ & UK LAI publication \\
\hline & Oppenheim & 2004 & Lean Product Development Flow & Systems Engineering \\
\hline & McManus & 2005 & $\begin{array}{l}\text { Lean Engineering: Doing the Right } \\
\text { Things Right }\end{array}$ & $\begin{array}{l}\text { 1st International } \\
\text { Conference on Innovation } \\
\text { and Integration in } \\
\text { Aerospace Sciences }\end{array}$ \\
\hline
\end{tabular}




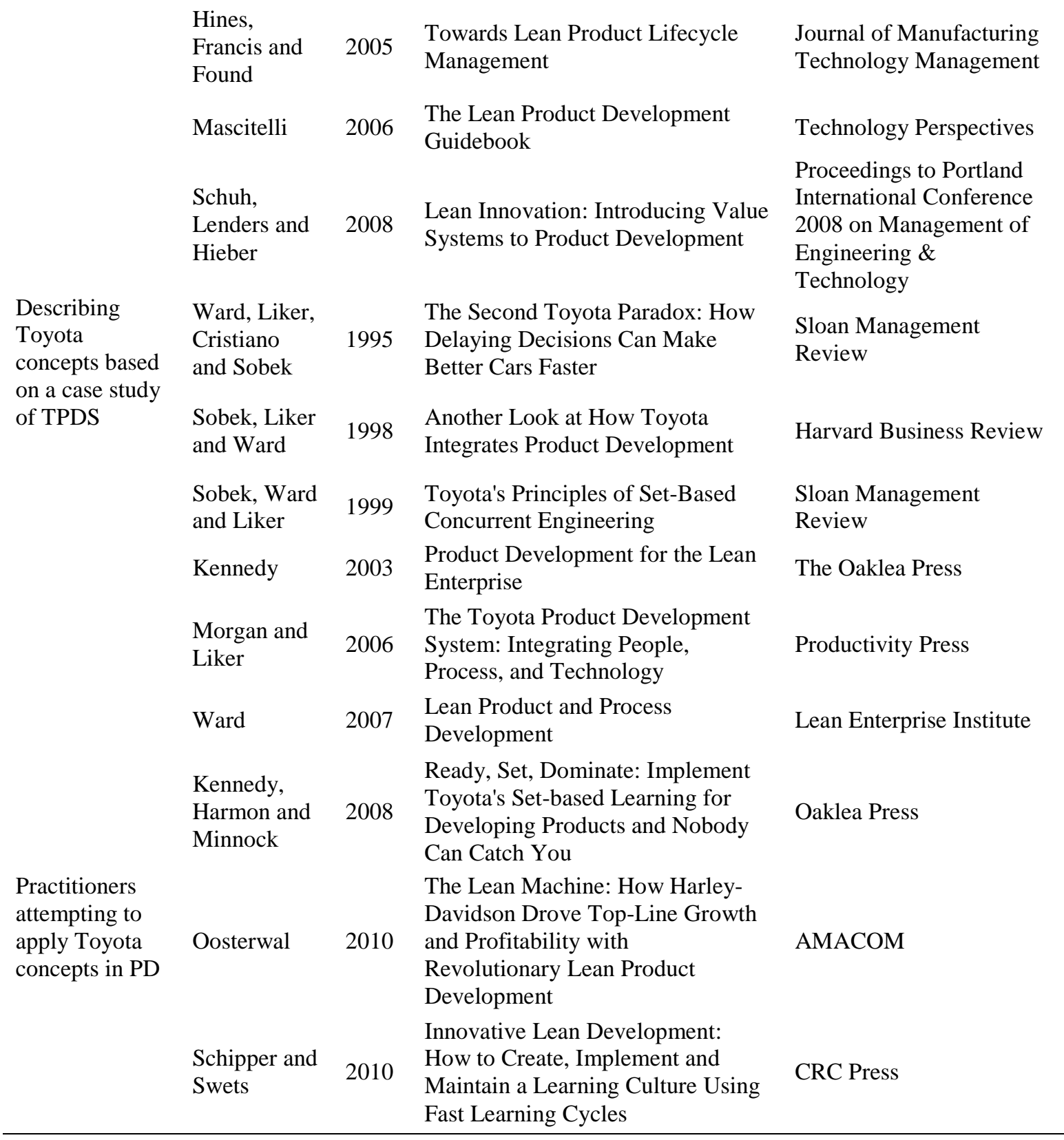

Benchmarking is not a new practise. Its origin is often quoted as the measurement of feet on a bench by cobblers, while later it was re-contextualised to company performance measurement (Cooper and Kleinschmidt 1995). The Japanese - while initiating their automobile industry used benchmarking when they visited the US automobile giants, as well as other European companies (Ohno 1988). The US used benchmarking in the International Motor Vehicle Program (IMVP) and the University of Michigan (UM) Toyota PD case study to evaluate and learn from Toyota and other Japanese companies. The global community develops as a whole and learns from each other to achieve excellence. This does not mean that one company will 
not outperform its competitors, nor does it mean that a company will disclose its advanced capabilities. Benchmarking however, must be done properly, and once complete should not be generalised as an all-encompassing solution. Those who adapted lean manufacturing to product development may have witnessed some short term benefits. However, lean manufacturing was extracted from the Toyota production system (TPS) and not the product development system (TPDS).

When you try to apply manufacturing principles and mechanisms to product development (PD) there are a number of inconsistencies: the output value is not a physical product received by a customer, eliminating waste does not identify poor quality, and value stream mapping (VSM) is based on the assumption that you have already got all the required valueadding steps in your process etc. Another assumption is that five principles are sufficient for PD as they were for manufacturing, however, Morgan and Liker - who based their work on a case study of Toyota PD - developed thirteen principles which were specific to PD (Morgan and Liker 2006).

Based on the analysis that has been described, the authors believe that Lean PD should refer to PD theory that is based on the critical elements of Toyota PD and not lean manufacturing. Once lean PD is established - based on Toyota PD - then it may evolve into a discipline in its own right. This was the case with lean manufacturing and similarly lean PD must not be constrained to Toyota practices, and must be a dynamic system that is always improving and responding to the challenges that PD faces. Currently research conducted in this area is limited and it must be steered in the right direction, to avoid mistakes in theory and practice.

\section{Progressing Towards Lean PPD}

The Toyota-centric Lean PD research that has been conducted describes Toyota PD principles and mechanisms, and their advantages over typical PD approaches. The research provides minimal evidence of the effectiveness of applying Toyota PD methods outside of Toyota. One reason for this is that the area of research is fairly new, and has been overshadowed by lean manufacturing and lean enterprise research. Another possible explanation may be a cultural barrier that inhibits the ideas of 'left-shifting work' and 
developing multiple alternative designs instead of a single design, which is the foundation of SBCE.

Based on the review of this research the authors believe that there are five core enablers of Toyota and indeed Lean PD:

1. Set-based concurrent engineering (SBCE) process

2. Chief engineer (entrepreneurial) technical leadership

3. Value-focused planning and development - this includes customer value, profit, amongst other attributes

4. Knowledge-based environment

5. Continuous improvement (Kaizen) culture

The authors propose the following definition for lean PD:

"Lean PD is value-focused PD. Value is a broad term used to define stake-holder needs and desires. SBCE is a strategic and convergent PD process guided by consistent technical leadership throughout. SBCE enables the focus on value and in particular knowledge and learning. Continuous improvement is the culture and an outcome of the SBCE learning process."

The authors believe that Toyota has developed their PD system to support these five core enablers and all other techniques and tools support them. Some may contest that the combination and management of people and tools are the foundation of Toyota PD, however many other companies have advanced management and organisational methods as well as state-of-the-art tools that may be equivalent or superior to their Toyota equivalents (Meyer 2008). The author believes that the chief engineer leadership system is however, an important enabler.

Through this review the authors identified that there is no comprehensive model that describes an integrated Lean PD process and framework. Subsequently there have been no structured attempts to perform a lean PD case study with an informative before and after measurement. A number of researchers have identified this gap and mentioned it as an area of future work in their concluding statements. Ward et al. (1995) suggested that Toyota's 
approach is not well defined or documented, and that methodologies need to be tested in different companies before formulating a complete theory. It may be said that significant effort has been made to define and document Toyota's approach; however different researchers have done so unilaterally. Further work is required to define the parameters of the lean PD research area and also to test the methodologies in different companies. Thus a complete and tested theory that integrates Lean PD into a holistic system which is transferable to other companies is yet to be established (McManus et al. 2005). Sobek et al. (1999) went to great lengths to study and document Toyota's SBCE approach, however, research is still required to construct a methodology for SBCE, integrated into a full PD process model that combines Toyota PD principles and mechanisms. This integrated model would require thorough investigation to substantiate its effectiveness and would need to be applied to a number of case studies across multiple engineering sectors in order to claim its general effectiveness for PD. Process-related factors have been downplayed by some academics who consider organizational strategies to be the key to success (Cusumano 1994; Cusumano and Nobeoka 1998). Although we do not dispute the importance of organizational strategy, it is vital to translate organizational strategy into processes in order to achieve enterprise success.

\section{The Building Blocks of Lean PD}

A framework of lean PD enablers was developed to represent lean PD. Methods, tools, and techniques that have been described by the researchers and practitioners who base their work on Toyota PD were documented and analysed. 21 lean PD enablers are agreed upon by consensus of these researchers (Ward et al., Morgan and Liker, Kennedy et al.), while 26 enablers were mentioned in a number of publications but not by consensus. This may be due to the research manuscript being incomplete such as in the case of Ward (2007), restricted to part of the puzzle (Ward et al. 1995; Sobek et al. 1999), or constrained to a particular case study (Kennedy 2006; Kennedy et al. 2008). The framework provides a categorisation of the 46 enablers; categories include core enablers, techniques, and tools. The core enablers for lean PD are depicted in figure 2 and their combination is referred to as the conceptual LeanPPD model. 


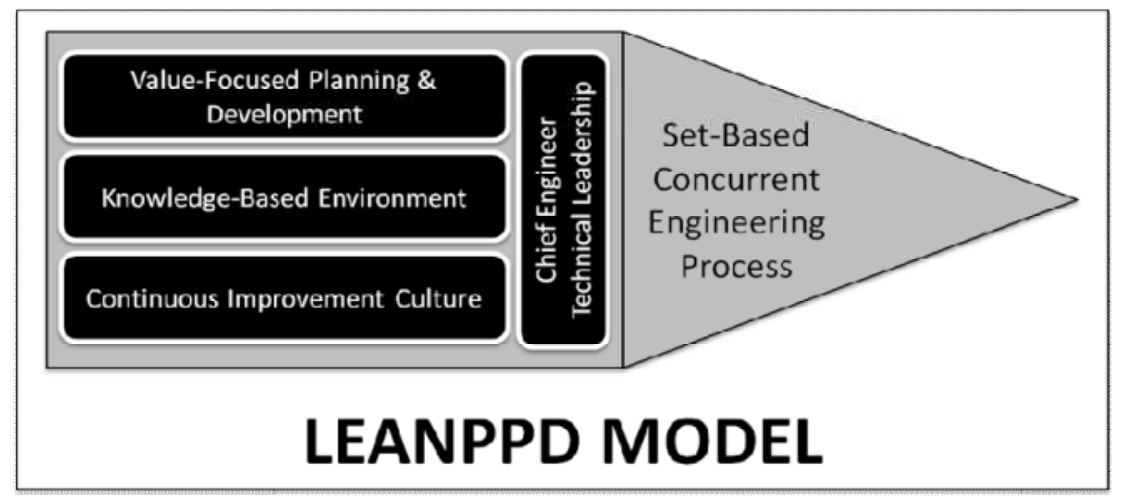

Figure 2 - The conceptual LeanPPD model

Set-based Concurrent Engineering (SBCE) is a unique product development process, and is considered the main enabler for Lean PD by some researchers (Ward 2007). Other enablers that have been described are either embodied within or support this process. Design participants practice SBCE by reasoning, developing, and communicating about sets of solutions in parallel. As the design progresses, they gradually narrow their respective sets of solutions based on the knowledge gained. As they narrow, they commit to staying within the sets so that others can rely on their communication (Sobek et al. 1999). The SBCE process is illustrated in Figure 3. SBCE comprises of a number of characteristics including exploring multiple alternatives, delaying specification, a minimal constraint policy ('delayed commitment'), extensive prototyping (or simulation), and convergence upon the optimum design. PD integration/target events are another important enabler. These events are unique design reviews used to guide the set-based process. Supplier strategy also resonates through the research, with the focus being on inter-locking key suppliers (keiretsu). Empowering suppliers to develop their own set-based approach can enable reduced supplier tracking and provide more room for innovation.

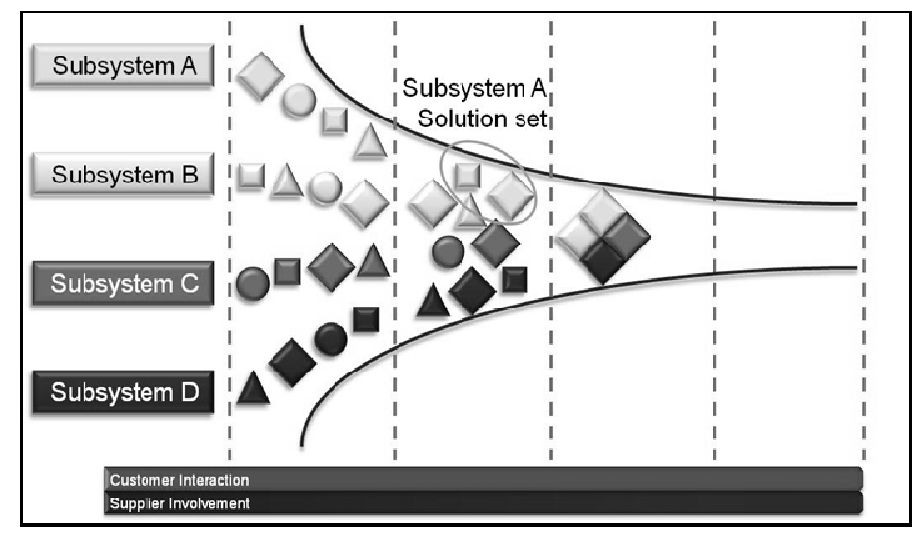


Figure 3 - Set-based concurrent engineering process

A number of additional design techniques are employed early in the design process, such as mistake proofing (Poke Yoke) and early problem solving, considering potential action scenarios to ensure conceptual robustness, and designing in quality. A design structures plan is also developed by each functional department to work out the main features of the design.

Another design technique that can support lean PD, is 'test-to-failure' (Ijiwara in Japanese), wherein prototypes are tested to breaking point. The aim of this technique is to learn more about designs and their thresholds, and produce 'limit curves' which capture the results. This technique forms part of the 'test-then-design' approach, wherein decisions are made after designs have been tested and factual knowledge (evidence) is provided. Matrices for comparing design concepts, and quality (e.g. quality function deployment) are also employed to aid in decision making.

The concept of value-focus is mentioned by all researchers, and the differentiation between product/customer value and process/enterprise value is also echoed (an example of process value is knowledge). Value stream mapping has also been mentioned briskly by all researchers, which may be indicative of its limited application in PD or lack of clarity as to how it should be applied. A strategic approach to product development is employed by Toyota which allows projects to be used to increase process value (knowledge, capabilities, etc.) A product portfolio is categorised into project types (facelift projects, minor modifications, major modifications, new product family etc.). Each category has a standard duration and follows a regular drumbeat with standard intervals. These development projects extract mature technologies from advanced technology teams that focus on research. Once a design is sufficiently mature for launch its release may be staggered to align with a multiproject plan that ensures the strategic launch of new products. This process is symbolic of the holistic systems thinking that Toyota applies to PD.

The Chief Engineer technical leadership is another enabler in which a technical leader is involved prior to conception and remains at the helm throughout the entire PD process. The 
chief engineer follows a shared company vision and is responsible for the production of a design concept document, which is used to communicate the vision for the product system. Cross-functional module development teams also play a role in the chief engineer system.

Another major enabler is a knowledge-based (KB) environment in which learning more about the design alternatives is the focus of PD activities. Ensuring knowledge is pulled by upstream processes as opposed to pushed by downstream processes is another important factor which ensures that knowledge flows and is received in the right place at the right time. Mechanisms for capturing, representing and communicating knowledge support the KB environment. These include: trade-off curves, check sheets, technical design standards and rules, and A3 single-sheet knowledge representations, which are primarily used for problem solving. These methods collectively provide a means for rapid communication and comprehension. Digital engineering including CAD, CAM, CAE, and other simulation software also support the KB environment. A learning organisation culture wherein employees are rewarded and appreciated for their technical contribution is another echoed enabler. Junior employees are mentored by senior employees who train their students how to approach technical problems in addition to passing on a wealth of tacit knowledge. Learning cycles such as PDCA (plan-do-check-act), and LAMDA (look-ask-model-discuss-act) represent the general problem solving approach. This collaboration sustains an expert workforce which is empowered to make decisions and do their own responsibility-based planning. Another enabler is a knowledge-based (KB) engineering system, also known as a 'know-how' database. The KB engineering system captures knowledge in a centralised database, with the capability to locate and extract required information easily. Another frequently employed technique is a lessons learnt process wherein experiences are reflected upon (Hansei in Japanese) and captured in the KB engineering system. Lessons learnt may also be published in books and provided to employees.

A culture for continuous improvement (Kaizen) in addition to formal methods to incorporate improvements have been suggested to be part of lean PD. Standardisation of processes, skills, and design methods allows continuous improvement to be regularly considered upon review. The Toyota approach to problem solving (Obeya in Japanese) is a pertinent example, where an A3-single sheet problem report is prepared and then used as the focal-point of collaborative meetings in team rooms. The aim is to share the problem, take 
counsel and arrive at a consensus for decisions. This often includes some root-cause analysis and an investigation known as ' 5 whys' where the source of a problem is identified.

A number of other enablers have been mentioned by a single researcher or group, and may be relevant enablers for lean PD. However due to the unilateral mention and based on the critical analysis conducted it is likely that they are not fundamental lean PD enablers.

The enablers for lean PD have been structured into a framework, presented in Table 2. The five core enablers are composed of techniques (methods or sub-enablers) and tools (hardware, software, documents etc.).

Table 2 Framework for Lean PD Enablers

\begin{tabular}{|c|c|c|}
\hline Core Enablers & Techniques & Tools \\
\hline \multirow{10}{*}{$\begin{array}{l}\text { Set-Based Concurrent } \\
\text { Engineering }\end{array}$} & Multiple alternatives (designed) & Design concepts matrix \\
\hline & Delaying specification & Quality matrix (QFD) \\
\hline & Minimal constraint & Design structures functional plan \\
\hline & $\begin{array}{l}\text { Extensive simulation/prototyping } \\
\text { (possibly including full-scale } \\
\text { models) }\end{array}$ & Design concept document \\
\hline & Early problem solving & $\begin{array}{l}\text { Digital engineering } \\
\text { (CAD/CAM/CAE/Simulation } \\
\text { etc.) }\end{array}$ \\
\hline & Test-then-design & \\
\hline & $\begin{array}{l}\text { Supplier strategy (supplier types and } \\
\text { interlocking) }\end{array}$ & \\
\hline & Supplier Set-Based Concurrent & \\
\hline & Engineering & \\
\hline & Mistake proofing & \\
\hline
\end{tabular}


Design in quality

Robust design methods

Integration/target events

Value-focus (planning and Value-stream mapping

development)

Customer-focus (customer

needs/wants)

Multi-project plan and strategy

\begin{tabular}{ll}
\hline Chief engineer technical & Cross-functional module \\
leadership & $\begin{array}{l}\text { development teams \& manufacturing } \\
\text { involvement }\end{array}$
\end{tabular}

Knowledge-focus

(knowledge-based

environment)
Knowlege/information
flow/cadence/pull (in right place at
right time)

Trade-off curves

Check sheets/lists

Knowledge reuse

$\mathrm{KB}$ engineering system (knowhow database)

Expert workforce development

Mentoring by senior employees

Test-to-failure

Limit curves

Rapid learning/comprehension

A3 group problem solving
A3 single-sheet problem reports 
Learning cycles (PDCA/LAMDA)

Root-cause analysis and 5 whys

\begin{tabular}{lll}
\hline $\begin{array}{l}\text { Continuous improvement } \\
\text { (Kaizen) culture }\end{array}$ & $\begin{array}{l}\text { Employee empowerment/individual } \\
\text { responsibility }\end{array}$ & $\begin{array}{l}\text { Technical design standards and } \\
\text { rules }\end{array}$ \\
& $\begin{array}{l}\text { Lessons learnt reflection process } \\
\text { Standardisation of processes, skills, } \\
\text { and design methods }\end{array}$ & $\begin{array}{l}\text { Standard architectures (and } \\
\text { modularity) }\end{array}$ \\
& $\begin{array}{l}\text { Separating research from } \\
\text { development }\end{array}$
\end{tabular}

In order to develop a complete LeanPPD model all or most of the above mentioned enablers should be present, and in particular the core enablers. Some of the techniques and tools may however, be replaced by an equal or superior equivalent.

\section{Lean PD in Industry}

Five engineering companies have been analysed as part of this research in order to search for evidence of the implementation of the lean PD enablers described in section 6. These include:

- one aerospace company that design and make engines for a number of sectors

- one automotive original equipment manufacturer company

- two automotive first tier supplier companies

- one home appliances original equipment manufacturer company

All of the companies face a variety of challenges in product development, including barriers to innovation, late design changes, communication issues, and knowledge related problems. The companies are interested in improving their processes, and the application of new methods and tools. Each of the companies do however face resource restrictions mainly due to economical factors. 
Initial interaction with industry involved various discussions through virtual web-based meetings, and face to face meetings at a number of European locations. Researchers also visited each of the five engineering companies at their locations and observed both PD and production activities. This included over 100 hours of interaction. PD documentation, depicting processes and models were provided for analysis. Meetings were held in order to understand industrial needs and to ensure an industrial-driven approach to the research.

Based on the understanding gained from the literature review and industrial visits, a structured questionnaire was developed. The questionnaire was used to guide the explorative study through face to face interviews with managers and engineers. It was important for these interviews to be face to face so that the behaviours and expressions of the candidates could be analysed and evidence could be requested by the interviewer for the answers provided. Thirty seven candidates have been interviewed from the five companies, including project managers, lead engineers, engineering managers, and design engineers. Each interview ranged from 90 to 120 minutes depending on the responses from the interviewees. Multiple interviews were conducted in the same company in order to gain a better overall picture, without losing the individual views and opinions. The survey was conducted between March and July of the year 2010 .

Results from the interviews were analysed qualitatively. The following considerations were made during the analysis of results in order to ensure the results represent PD and not just the individual, without neglecting individual opinions and perceptions:

- Role in organisation: Responses from managers were weighted higher for questions that were related to organisational processes, while responses from engineers were weighted higher for design methods and tools employed in PD.

- Years of experience: Responses from interviewees who have been working for the organisation for a longer duration were generally weighted higher, as they often had a better understanding of PD at their organisation

- Consensus: Where there was a consensus of responses, it was quite certain that the answer was representative of the organisation, whereas if the answers varied then further analysis was required to provide a single representative result or a combined result representing different opinions or views 
- Incorrect responses: Some interviewees guessed, or answered without the required knowledge, such answers generally became apparent to the interviewer and were logged during the interview, and in some cases became apparent when comparing results

- Transcripts: Notes taken during the interviews were consulted while analysing results, to ensure the context of each answer was understood and in some cases the behaviour of the interviewees

The questionnaire was used to investigate whether or not the 46 enablers depicted in table 2 have been formally implemented through direct and indirect questions. Examples of the question that were asked include:

(1) Do you have flexibility in how you do your job?

(2) Is there a technical leader who is responsible for the entire development of a product from concept to launch?

(3) Every specification is a compromise between what customers want and what can be provided. How is a product specification stabilised in your product development process?

(4) How do you select the design solution that will be developed?

(5) How are your current processes and work methods reviewed/improved?

(6) Do manufacturing (production) engineers play an active role in each stage of product development?

(7) Do your suppliers provide you with multiple alternatives for a single part (component)?

(8) How are projects currently initiated, and the does the product development process flow?

The results show that a number of lean PD enablers have been employed in the companies that were studied. However, the companies have not formally implemented the majority of lean PD enablers as can be seen in Figure 4. 


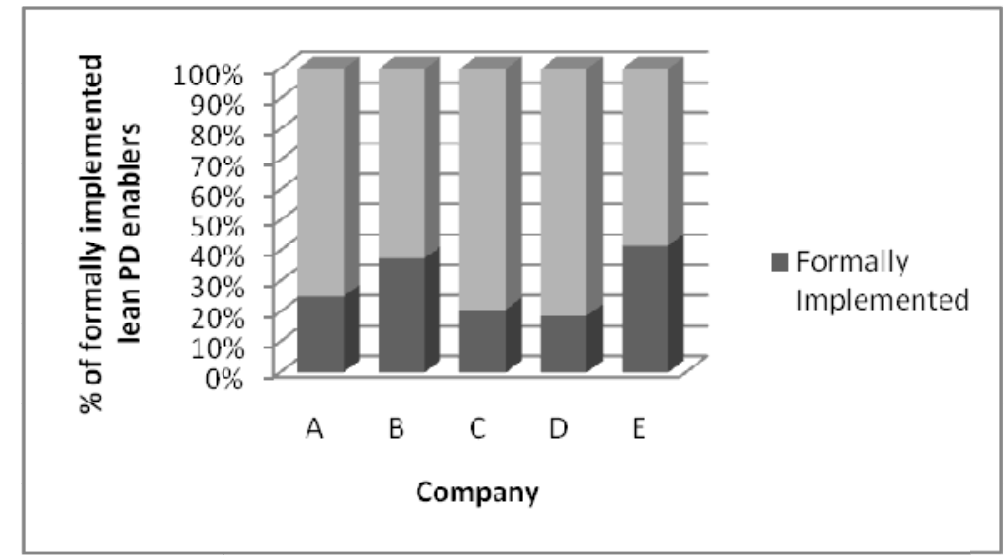

Figure 4 - Percentage of Lean PD Enablers that Companies A-E have Formally Implemented in their PD Processes

One company has formally implemented a set-based approach in the concepts stage of their PD, considering multiple alternatives and performing extensive simulation and prototyping. Two companies have tested a set-based approach informally, but do not progress alternatives sufficiently. However none of the companies intentionally delay their specification of products and they tend to work in a constrained design space that limits their innovation and prevents convergence upon optimum designs. This means that a SBCE process could be a significant contribution to each of the five industrial partner companies.

Three of the companies employ a supplier strategy in which some suppliers are interlocked with the company, while others are given less flexibility to design components. Suppliers to these companies do not employ SBCE, but they do sometimes offer alternative solutions based on a rough specification.

One company formally implements a chief engineer system, wherein a technical leader is personally involved in market research and is technically responsible for a product from concept to launch. However, as in the other companies, a non-technical project manager is always managing the project. Another company has trialled this approach informally and witnessed substantial results. Other companies do employ technical leaders but they tend to be appointed after the concept stage or there are multiple leaders that lead different stages of 
PD. This implies that the demonstration of consistent technical leadership for the full product life-cycle could yield significant results.

All of the companies employ a systems engineering approach with a combination of specification and requirements documents. Cross-functional module development teams are only employed in one of the companies, however they are formed late in the design process. Manufacturing engineers tend to be involved in the design of products and their level of involvement increases as the project develops, however only 3 of the companies involve them in the concept stage albeit minimally.

Knowledge tends not to be pulled; rather it is pushed onto engineers, however almost all interviewees suggested that most design problems would be solved if the correct knowledge was in the right place at the right time. It was also found that most of the interviewees spend $80 \%$ of their time on routine tasks, with the exception of one company that puts special emphasis on innovation. However, none of the companies focus primarily on learning and increasing enterprise knowledge. Evidence for the use of trade-off curves was found in one company, however checklists were employed in all companies with varied usage and effectiveness.

Lessons learnt are captured by all of the companies, but are not used effectively. However one company has a formal lessons learnt strategy which captures lessons from each project by employees who are encouraged to make suggestions which are fed back into the processes. The majority of interviewees stated that they were always overburdened by the quantity of work, with the exception of one company where the engineers did not agree that this was the case as opposed to the managers who thought it was.

A3 group problem solving is employed by 2 of the companies during design, both of which follow a plan-do-check-act learning cycle. One of these companies find it difficult to follow as the meetings are generally virtual and a single-sheet representation is not always used, while the other company finds that different departments vary in their methodologies.

Mistake proofing is considered where possible in all of the companies, but there is no evidence that it is formally analysed as part of their PD processes. Design for six sigma is used sometimes by 3 of the companies to 'design in' quality to the designs, but it is 
considered only somewhat effective by most. Robust design and Taguchi methods are also used in two of the companies.

It was found that at the systems level products follow a drumbeat and are designed as part of a strategy with different product types (redesign, major modification, minor modification, facelifts etc.). However, first tier suppliers respond to customer requests, often in competition with other suppliers. Projects tend to run late, and activities are often sacrificed in order to meet launch dates. Only one of the companies has a separate (dedicated) research department, which offers mature technology to new products. Other companies have research and development departments that push their technology onto new products.

The results show that most of the lean PD enablers have a presence in industry, but different companies excel in the implementation of specific enablers. These enablers tend to be developed in-house or imported from a parent (or another) company and lack the benefits of academic support. Many of the lean PD enablers are intuitive, which explains their informal application, however participants suggested that cultural and organisational barriers are likely to be the main inhibitors. Another problem is the misunderstanding that lean PD is lean manufacturing applied to PD. Once the participants were provided with information about lean PD, they were welcoming to the new ideas, they did however want to see the results of a real case study before considering any formal implementation. There remains a need for generic and formal research-based methodologies, techniques and tools to embed Lean PD enablers into PD.

\section{Conclusions and Future Work}

This paper provides the methodology adopted in order to pave the way towards the development of a coherent lean PD model that is fundamentally based on the Toyota PD system. A systematic review has been conducted in which the various approaches towards lean PD have been analysed and categorised. Based on the review, Lean PD has been defined as follows:

"Lean PD is value-focused PD. Value is a broad term used to define stake-holder needs and desires. SBCE is a strategic and convergent PD process guided by consistent technical 
leadership throughout. SBCE enables the focus on value and in particular knowledge and learning. Continuous improvement is the culture and an outcome of the SBCE learning process."

Previous research provides minimal evidence of the effectiveness of applying Toyota PD methods outside of Toyota. One reason for this is that the area of research is fairly new, and has been overshadowed by lean manufacturing and lean enterprise research. Another possible explanation may be a cultural barrier that inhibits the ideas of 'left-shifting work' and developing multiple alternative designs instead of a single design, which is the foundation of set-based concurrent engineering (SBCE). Further research is required to progress lean PD into a discipline in its own right.

The building blocks of Toyota PD which support five core enablers have been structured in a framework which can be used as a reference for the key constituents of Toyota PD, which is our best reference for Lean PD. The authors have collaborated with 5 engineering companies and conducted structured interviews in each of them to search for evidence of the implementation of lean PD enablers. Some of these enablers have been informally applied in the companies, and a few have been formally implemented. However, no PD model was found that formally combines the enablers into a coherent whole. This shows that there is a need to demonstrate the conceptual LeanPPD model and assess its impact on PD. If a lean PD model is developed which addresses the current challenges faced by industry, companies may consider adopting it. Through our interactions with industry we have identified a keen interest in the combination of the core enablers. The companies did not want to be provided with isolated tools; rather they would prefer to implement lean PD using their existing tools and techniques.

The impact of the individual lean PD enablers do however need to be investigated to determine their effectiveness and relevance within a Lean PD model. Future work that is currently in progress involves developing the LeanPPD Model based primarily on the five core enablers. The model will facilitate the integration of best practises from Toyota and other companies that are best suited to support the core enablers. Future research may also include the development and implementation of methods and tools that support the hypotheses in this paper. While this research provides direction for developing a lean PD 
model, organisational, human resource and cultural factors need also to be considered as processes are implemented by people.

\section{Acknowledgements}

The research presented in this paper has been conducted as part of a European project titled 'Lean Product and Process Development (LeanPPD)'. The project involves multiple research and industrial partners from the UK, Spain, Germany, Italy and Poland. The project is supported by the Commission of European Community, (contract number NMP-2008214090) under the NMP Programme (Nanosciences, Nanotechnologies, Materials and new Production Technologies). Authors wish to acknowledge the European Commission for its support as well as the other partners in the consortium (http://www.leanppd.eu). 


\section{References}

BAINES, T., LIGHTFOOT, H., WILLIAMS, G.M. and GREENOUGH, R., 2006. State-of-the-art in lean design engineering: a literature review on white collar lean. Proceedings of the Institution of Mechanical Engineers, Part B: Journal of Engineering Manufacture, 220(9), pp. 1539-1547.

BAINES, T.S., LIGHTFOOT, H.W., EVANS, S., NEELY, A., GREENOUGH, R., PEPPARD, J., ROY, R., SHEHAB, E., BRAGANZA, A. and TIWARI, A., 2007. State-of-the-art in product-service systems. Proceedings of the Institution of Mechanical Engineers, Part B: Journal of Engineering Manufacture, 221(10), pp. 1543-1552.

BROWNING, T.R., 2003. On customer value and improvement in product development processes. Systems Engineering, 6(1), pp. 49-61.

COOPER, R.G. and EDGETT, S.J., 2005. Lean, Rapid, and Profitable New Product Development. Product development institute.

COOPER, R.G. and KLEINSCHMIDT, E.J., 1995. Benchmarking the firm's critical success factors in new product development. Journal of Product Innovation Management, 12(5), pp. 374-391.

CUSUMANO, M.A., 1994. The Limits of" Lean". Sloan management review, 35, pp. 27-27.

CUSUMANO, M.A. and NOBEOKA, K., 1998. Thinking beyond lean. Free Press.

DUVERLIE, P. and CASTELAIN, J., 1999. Cost estimation during design step: parametric method versus case based reasoning method. The international journal of advanced manufacturing technology, 15(12), pp. 895-906.

FIORE, C., 2003. Lean strategies for product development: achieving breakthrough performance in bringing products to market. American Society for Qualit.

HAQUE, B. and JAMES-MOORE, M., 2004. Applying lean thinking to new product introduction. Journal of Engineering Design, 15(1), pp. 1-31.

HINES, P., FRANCIS, M. and FOUND, P., 2006. Towards lean products life cycle management. Journal of Manufacturing Technology Management, 17(7), pp. 866-887.

HINES, P., PACKHAM, J. and PARTNERS, S.A., 2008. Implementing lean new product development, 2008, pp. 1462-1467.

HOLWEG, M., 2007. The genealogy of lean production. Journal of Operations Management, 25(2), pp. 420437.

HUTHWAITE, B., 2004. The lean design solution: a practical guide to streamlining product design and development. 2 (2007) edn. Mackinac Island: Institute for Lean Innovation.

KARLSSON, C. and AHLSTROM, P., 1996. The difficult path to lean product development. Journal of Product Innovation Management, 13(4), pp. 283-295.

KENNEDY, M.N. and WARD, A., 2003. Product development for the lean enterprise: why Toyota's system is four times more productive and how you can implement it. Oaklea Press.

KENNEDY, M., HARMON, K. and MINNOCK, 2008. Ready, set, dominate : implement Toyota's set-based learning for developing products and nobody can catch you. Richmond, Va.: Oaklea Press. 
KHALIL, R.A. and STOCKTON, D.J., 2010. Predicting the effects of cycle time variability on the efficiency of electronics assembly mixed-model, zero-buffer flow processing lines. International Journal of Computer Integrated Manufacturing, 23(12), pp. 1149-1157.

MASCITELLI, R., 2006. The lean product development guidebook: everything your design team needs to improve efficiency and slash time-to-market. Technology Perspectives.

MCMANUS, H.L., HAGGERTY, A. and MURMAN, E., 2005. Lean engineering: doing the right thing right, Proceedings of the 1st International Conference on Innovation and Integration in Aerospace Sciences, Queen's University Belfast, Northern Ireland, UK 2005.

MEYER, M.H., 2008. PERSPECTIVE: How Honda Innovates*. Journal of Product Innovation Management, 25(3), pp. 261-271.

MOLINA, A., ACA, J. and WRIGHT, P., 2005. Global collaborative engineering environment for integrated product development. International Journal of Computer Integrated Manufacturing, 18(8), pp. 635-651.

MORGAN, J.M. and LIKER, J.K., 2006. The Toyota product development system: integrating people, process, and technology. New York: Productivity Press.

MURMAN, E.M., WALTON, M. and REBENTISCH, E., 2000. Challenges in the better, faster, cheaper era of aeronautical design, engineering and manufacturing. Aeronautical Journal, 104(1040), pp. 481-489.

MYNOTT, C., 2000. Lean Product Developmen: the manager's guide to organising, running and controlling the complete business process of developing products. Westfield Publishing.

OHNO, T., 1988. Toyota production system: beyond large-scale production. Cambridge: Productivity Press.

OOSTERWAL, D.P., 2010. The Lean Machine: How Harley-Davidson Drove Top-Line Growth and Profitability with Revolutionary Lean Product Development. AMACOM/American Management Association.

OPPENHEIM, B.W., 2004. Lean product development flow. SYSTEMS ENGINEERING-NEW YORK-, 7(4), pp. 352-378.

PAWAR, K.S., BELTAGUI, A. and RIEDEL, J.C.K.H., 2009. The PSO triangle: designing product, service and organisation to create value. International Journal of Operations and Production Management, 29(5), pp. 468493.

REINERTSEN, D.G., 2009. The principles of product development flow: second generation lean product development. Celeritas.

SCHIPPER, T.H. and SWETS, M.D., 2009. Innovative lean development: how to create, implement and maintain a learning culture using fast learning cycles. Productivity Pr.

SCHUH, G., LENDERS, M. and HIEBER, S., 2008. Lean innovation: introducing value systems to product development, Management of Engineering \& Technology, 2008. PICMET 2008. Portland International Conference on 2008, pp. 1129-1136.

SOBEK, D.K., WARD, A.C. and LIKER, J.K., 1999. Toyota's principles of set-based concurrent engineering. Sloan management review, 40(2), pp. 67-84.

SOBEK, I., DURWARD, K. and LIKER, J.K., 1998. Another look at how Toyota integrates product development. Harvard business review, 76(4), pp. 36.

WARD, A., LIKER, J.K., CRISTIANO, J.J. and SOBEK, D.K., 1995. The second Toyota paradox: How delaying decisions can make better cars faster. Sloan management review, 36, pp. 43-43. 
WARD, A.C., 2007. Lean product and process development. Cambridge, USA: Lean Enterprise Institute.

WOMACK, J.P. and JONES, D.T., 2003. Lean Thinking: Banish waste and create wealth in your organisation. London: Simon \& Schuster UK Ltd.

WOMACK, J.P., JONES, D.T. and ROOS, D., 1990. The machine that changed the world. Rawson Associates New York.

YELKUR, R. and HERBIG, P., 1996. Global markets and the new product development process. Journal of Product \& Brand Management, 5(6), pp. 38-47. 